\title{
Cystathionine $\beta$-Synthase Deficiency: A Qualitative Abnormality of the Deficient Enzyme Modified by Vitamin $B_{6}$ Therapy
}

\author{
RICCARDO C. LONGHI, LYNN D. FLEISHER, HARRIS H. TALLAN, AND GERALD E. GAULL ${ }^{(2)}$ \\ Department of Pediatric Research, New York State Institute for Basic Research in Mental Retardation, Staten Island, \\ New York; and Department of Pediatrics and Clinical Genetics Center, Mount Sinai School of Medicine of the City
} University of New York, New York, New York, USA

\begin{abstract}
Summary
The thermostability of cystathionine synthase and the effect of pyridoxal phosphate (PLP) on this thermostability were investigated in extracts of normal human liver and in extracts of liver, both before and during pyridoxine (vitamin $B_{6}$ ) therapy, from members of a family with three clinically and biochemically typical, $B_{6}$-responsive, synthase-deficient sibs.

Incubation of crude extracts of normal liver at $55^{\circ}$ (preincubation) for 3-4 min before assay consistently resulted in a more than 2 -fold increase in specific activity (activation) of cystathionine synthase (Fig. 1). With periods of preincubation longer than $4 \mathrm{~min}$, thermal inactivation occurred. When PLP was added to the preincubation mixture, slightly more activation occurred in the first 3-4 min, and there was no observable loss of activity for an additional $25 \mathrm{~min}$.

The activation phenomenon was not observed in extracts of liver which had been obtained from three synthase-deficient sibs before therapy with vitamin $B_{6}$ (Index of activation, Table 1 ). When extracts of liver obtained during vitamin $B_{6}$ therapy were studied, however, significant activation was observed. Synthase activity in extracts of liver from the patients' parents, obligate heterozygotes for synthase deficiency, and from a potentially heterozygous sister demonstrated activation similar to that found in control liver extracts.

With periods of preincubation longer than $5 \mathrm{~min}$, the inactivation of synthase in liver extracts from patients receiving pyridoxine-HCl occurred at the same rate as in liver extracts from heterozygotes and from normal subjects (Index of inactivation, Table 1). PLP completely prevented heat inactivation of enzyme from normal liver.
\end{abstract}

\section{Speculation}

Activation of cystathionine synthase is an expression of the ability of the normal enzyme to undergo heat-induced conformational changes. The failure to activate the abnormal enzyme suggests it has an altered molecular structure.

Cystathionine $\beta$-synthase (EC. 4.2.1.22), in the presence of the coenzyme, PLP, catalyzes the condensation of homocysteine and serine to form cystathionine. Synthase deficiency (21), which is inherited in an autosomal recessive manner (7), results in the clinical syndrome of homocystinuria $(3,19)$. The precise nature of the mutation(s) responsible for the deficiency is unknown. Some patients respond biochemically to massive doses of vitamin $\mathrm{B}_{6}$ in the form of pyridoxine- $\mathrm{HCl}$ (Reference 1 ; also $c f$. Reference 4) and this response usually is accompanied by a significant increase in hepatic synthase activity $(11,20)$. The mechanism by which vitamin $B_{6}$ effects an increase in synthase activity, however, remains unclear. In general, a genetically determined deficiency of enzymatic activity may result from decreased holoenzyme synthesis (due to decreased apoenzyme or coenzyme formation or to their altered association), from decreased enzyme stability, and/or from decreased efficiency of the enzyme (decreased activity per mg enzyme protein). Consequently, vitamin $B_{6}$ may increase the steady state activity of hepatic synthase in $B_{6}$-responsive, synthase-deficient patients by affecting one or more of these mechanisms.

Heat stability studies have proved useful in comparing genetically determined variants of an enzyme. In addition, PLP has been shown to retard the in vitro inactivation by heat and/or proteases of certain PLP-dependent enzymes $(12,23)$. In light of this, we have investigated the thermostability of cystathionine synthase, and the effect of PLP on this thermostability, in extracts of normal human liver and in extracts of liver, both before and during vitamin $B_{6}$ therapy, from a family with three synthase-deficient sibs. All three sibs are $B_{6}$ responsive and are clinically and biochemically typical.

\section{METHODS}

Control liver was obtained at autopsy 5-24 hr after death or was part of a biopsy taken during abdominal surgery. Biopsies of liver from members of the affected family were obtained percutaneously with a Menghini needle. Informed consent was obtained in writing. Vitamin $B_{6}$ therapy was administered orally for 2-12 weeks before repeat biopsy ( $c f$. legend, Table 1).

Liver specimens were homogenized in 7 volumes $0.03 \mathrm{M}$ phosphate buffer ( $\mathrm{pH} 6.9$ ) and centrifuged for $1 \mathrm{hr}$ at $40,000 \times$ $g$. The supernatant solution was used for the enzymatic studies. Partially purified extracts were prepared according to the method of Tallan et al. (24). Tissue extracts were incubated at $55^{\circ}$ for varying lengths of time before assay (preincubation) in the presence or absence of $1.3 \mathrm{mM}$ PLP (final volume $70 \mu \mathrm{l}$ ). The reaction tubes were then plunged into crushed ice for $15 \mathrm{~min}$ before assay at $37^{\circ}$. PLP was added where previously omitted to equalize the concentration present during the assay. Conditions for assaying liver extracts were modified from the method of Gaull et al. (10) by incubating at $\mathrm{pH} 8.4$ for $45 \mathrm{~min}$. The assay procedure is based on the direct measurement, on an automatic amino acid analyzer, of cystathionine formed in the reaction.

Protein concentration was determined according to the method of Lowry et al. (17). Enzymatic activity is expressed as nanomoles of cystathionine formed per $\mathrm{mg}$ protein per $\mathrm{hr}$. When activity is expressed as a percentage, $100 \%$ refers to enzyme which was not preincubated (zero time).

\section{RESULTS}

Crude extracts of normal liver obtained at autopsy were preincubated at $55^{\circ}$ for periods up to $4 \mathrm{~min}$ before assay. This consistently resulted in at least a 2 -fold increase in specific 
activity (activation) of cystathionine synthase (Fig. 1). Preincubation for periods longer than $4 \mathrm{~min}$ resulted in a typical curve of thermal inactivation, which, in replicate experiments, appeared to level off at 20-30 min. When PLP was added to the preincubation mixture, somewhat more activation occurred during the first $4 \mathrm{~min}$; no observable loss of activity occurred during the following $25 \mathrm{~min}$. Because of the small amounts of liver obtained with a needle. fixed preincubation times of 3 and 10 min were selected for study of biopsied liver. The 3-min preincubation time was chosen because in preliminary experiments this consistently was the time of maximal activation; the 10 -min preincubation time was chosen because it consistently was on the linear portion of the descending curve.

Preincubation of extracts of control biopsy material for $3 \mathrm{~min}$ at $55^{\circ}$ resulted in a 2- to 3 -fold increase in specific activity over the mean specific activity of extracts which were not preincubated (zero time value) (Table 1). After a 10-min preincubation. the specific activity was still higher than at zero time, although substantially decreased from the specific activity observed after the 3-min preincubation. Preincubation for $10 \mathrm{~min}$ in the presence of $1.3 \mathrm{mM}$ PLP resulted in activities which were much higher than those observed after a $1(0-\mathrm{min}$ preincubation without added PLP, indicating protection against heat inactivation. The higher relative specific activity at $10 \mathrm{~min}$ in the presence of PLP is also a function of the greater activation achieved in the presence of the coenzyme (see Fig. 1). Liver obtained 5-24 hr after death had lower activity than liver obtained in vivo, although the patterns of response to heat were similar.

Extracts of liver from three synthase-deficient sibs obtained before treatment with pyridoxine had specific activities of 16 . 14. and 9, respectively (Table 1 ), 4-7\% of the mean control value. The activation phenomenon did not occur in extracts of liver from the two sibs from whom enough liver was obtained for heat stability studies. On the contrary, a lower specific activity was found both after 3-min and after 10 -min preincubation than was found without preincubation.
When these studies were performed on extracts of liver obtained from the three affected sibs during vitamin $B_{6}$ therapy, the results were strikingly different (Table 1). The specific activity of cystathionine synthase in liver extracts which were not preincubated was found to have increased in sibs 2 and 3 (from 14 to 24, and from 9 to 19), but not in sib $l$ (who was receiving a smaller dose of vitamin $B_{6} ; c f$. legend, Table 1 ). In addition, significant activation was now observed in all cases after 3 min of preincubation at $55^{\circ}$. After $10 \mathrm{~min}$ of preincubation, synthase activities decreased from those found after a 3 -min preincubation.

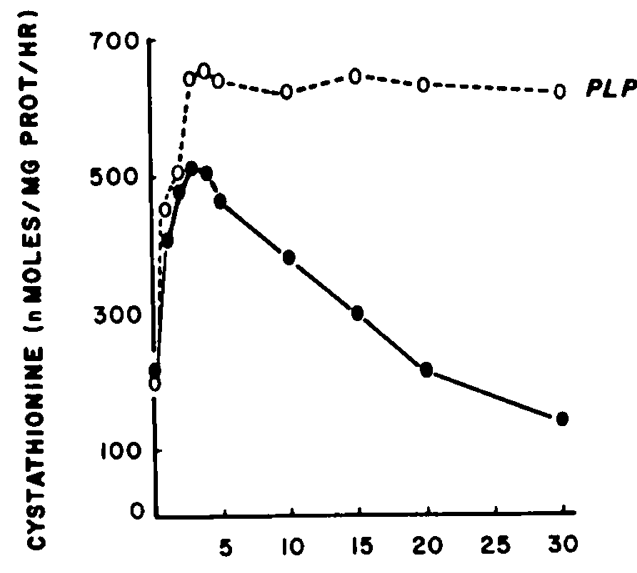

MINUTES PREINCUBATION AT $55^{\circ}$

Fig. 1. Effect of preincubation at $55^{\circ}$ on specific activity of cystathionine $\beta$-synthase in a crude extract of human liver. These data represent one of four replicate experiments, using different enzyme extracts, which showed identical patterns of thermostability. preincubation without added pyridoxal phosphate (PLP); $O_{---O}$ preincubation in presence of $1.3 \mathrm{mM}$ PLP.

Table 1. Heat-induced activation and inactivation of human hepatic cystathionine synthase: Effects of pyridoxine ( $\left.B_{6}\right)$ in vivo and of

\begin{tabular}{|c|c|c|c|c|c|c|c|}
\hline \multirow[b]{2}{*}{ Subjects } & \multirow{2}{*}{$\begin{array}{l}\text { Cystathionine syn- } \\
\text { thase specific activity2 }\end{array}$} & \multicolumn{4}{|c|}{$\begin{array}{l}\text { Relative specific activity after preincubation at } 55^{\circ} \\
\text { for time (min) indicated }\end{array}$} & \multirow{2}{*}{$\begin{array}{c}\text { Index of ac- } \\
\text { tivation } \\
(3 / 0)^{4}\end{array}$} & \multirow{2}{*}{$\begin{array}{l}\text { Index of } \\
\text { activation } \\
(10 / 3)^{5}\end{array}$} \\
\hline & & 0 & 3 & 10 & $10+$ PLP & & \\
\hline \multicolumn{8}{|l|}{ Before $B_{t ;}$ therapy } \\
\hline Controls & $225 \pm 7^{i}(5)$ & 100 & $26.3 \pm 42^{6}$ & $179 \pm 14$ & $356 \pm 34$ & 2.63 & 0.70 \\
\hline \multicolumn{8}{|l|}{ Affected sibs } \\
\hline 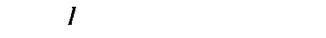 & 16 & 100 & 38 & 60) & & 0.38 & 7 \\
\hline 2 & 14 & 100 & 88 & 89 & & 0.88 & 7 \\
\hline 3 & 9 & 100 & & & & & \\
\hline \multicolumn{8}{|l|}{ Obligate heterozygotes } \\
\hline Mother & 88 & 100 & 298 & 154 & & 2.98 & 0.52 \\
\hline Father & 147 & 100 & 257 & 192 & & 2.57 & 0.75 \\
\hline Potential heterozygote & 176 & 100 & 264 & 164 & & 2.64 & 0.62 \\
\hline \multicolumn{8}{|l|}{ After $B_{6}$ therapy } \\
\hline \multicolumn{8}{|l|}{ Affected sibs } \\
\hline$l$ & 15 & 100 & 210 & 151 & & 2.1 & 0.74 \\
\hline 2 & 24 & 100 & 174 & 126 & & 1.74 & 0.72 \\
\hline 3 & 19 & 100 & 137 & 61 & & 1.37 & 0.45 \\
\hline \multicolumn{8}{|l|}{ Obligate heterozygote } \\
\hline Father & 199 & 100 & 233 & 128 & & 2.33 & 0.55 \\
\hline
\end{tabular}

1 Numbers in parentheses refer to number of subjects studied in duplicate. Control liver was obtained from specimens taken from open biopsies which were clinically indicated and in which clinical decision the investigators did not participate.

${ }^{2}$ Nanomoles of cystathionine per $\mathrm{mg}$ protein per hr, equal to value without preincubation at $55^{\circ}$ (zero time value).

${ }^{3}$ Percentage of zero time value.

4 Specific activity after a $3-$ min preincubation at $55^{\circ}$ divided by the specific activity without preincubation at $55^{\circ}$ (zero time value).

${ }^{5}$ Specific activity after a 10 -min preincubation at $55^{\circ}$ divided by the specific activity after a 3 -min preincubation at $55^{\circ}$.

"Mean \pm SEM

$7 \mathrm{~A}$ comparison of these data with other values is not valid because of the absence of activation in untreated patients.

"Pyridoxine- $\mathrm{HCl}$ was administered orally to sib $l(50 \mathrm{mg} / \mathrm{day})$ for 12 weeks, to sibs 2 and $3(250 \mathrm{mg} / \mathrm{day})$ for 2 weeks, and to the father (250) mg/ day) for 8 weeks before biopsy. 
Synthase activities in liver extracts from the patients' parents. obligate heterozygotes for synthase deficiency. were intermediate between those found in extracts of nomal liver and those found in extracts of liver from the patients (39\% of mean control in the case of the mother and $65 \%$ in the case of the father). A 3min preincubation resulted in an activation similar to that seen in extracts from normal liver. After a 10-min preincubation, there was a decrease in specific activities of synthase from those found after a 3-min preincubation. Extracts of liver from the father. obtained during vitamin $B_{6 i}$ administration, had a higher specific activity of synthase than was present in a similar extract obtained before administration of vitamin $B_{t i}$. The response of synthase activity to preincubation at $55^{\circ}$ was again entirely similar to the response of synthase activity in extracts of normal liver. The specific activity of synthase in extracts of liver from the potentially heterozygous sister of the affected sibs was $176(77 \%$ of the mean control value) and the response of the enzyme extract to heat was similar to that of the control subjects.

\section{DISCUSSION}

A genetically determined enzymatic deficiency may result from the alteration of any one of a complex series of reactions: apoenzyme synthesis, coenzyme formation and transport, apoenzyme-coenzyme association, and degradative processes. A presumed decrease in coenzyme formation, transport, or association with apoenzyme has been the rationale behind megatherapy with a number of vitamins, including the $B_{6}$ vitamins (which most likely act through the coenzymatically active form. PLP). Vitamin $B_{6}$, however, may affect enzymatic activity in other ways: e.g., pyridoxine induces rat liver tyrosine $\alpha$-ketoglutarate transaminase activity in vivo by increasing the rate of enzyme synthesis (12)

The mechanism by which massive doses of pyridoxine increase the steady state activity of cystathionine synthase in some patients with $B_{t}$-responsive synthase deficiency $(11,20)$ is still unclear. Our data confirm and extend previous reports $(14,20)$ of an in vitro protective effect of PLP against heat inactivation and demonstrate the magnitude of this effect (Fig. 1). Such protection may reflect a decreased dissociation of coenzyme and apoenzyme in the presence of exogenous PL.P. thereby maintaining the holoenzyme in its active and most stable molecular conformation (16). We have found that PLP completely prevents any loss of hepatic synthase activity due to heat denaturation during a 3()$-\mathrm{min}$ exposure at $55^{\circ}$ (Fig. 1). Mudd et al. (20) have reported that PLP is as effective in preventing heat inactivation of enzyme from patients as it is in preventing heat inactivation of enzyme from normal subjects and from heterozygotes. Because of the small amount of liver obtained from our patients, we were unable to investigate this point.

A clear distinction between normal and abnormal synthase is found in the ability of normal synthase to undergo heat-induced activation, a property of cystathionine synthase demonstrated for the first time in the present study. The activity of normal enzyme, as well as that of enzyme from obligate heterozygotes, is strikingly increased by preincubation at $55^{\circ}$ for $3 \mathrm{~min}$. Such preincubation, on the contrary, decreases the activity of the enzyme from the patients (Index of activation, Table 1 ). If we assume that activation is an expression of the ability of normal synthase to undergo heat-induced conformational changes, the failure to activate demonstrated by the abnormal enzyme is an indication of an altered molecular structure.

The occurrence of increased enzymatic activity after exposure to heat is unusual, but not unique, among human enzymes. Similar results have been reported for phosphoglucomutase (18) and mannosidase (2). Heat-induced activation of cystathionine synthase appears to be a general characteristic of the enzyme, for we have demonstrated it in the following crude extracts: cultured human skin fibroblasts, cultured lymphoid cell lines, human brain, and liver and brain of rat and monkey (8). It is present also in partially purified extracts of human liver. Heat- induced activation of cystathionine synthase was not reported by other workers $(14,20)$; however, our experiments are not completely comparable with theirs. Activation of cystathionine synthase by trypsin (20), by $S$-adenosylmethionine (6), and by $S$ adenosylhomocysteine $(5)$ have been reported. The relationship of these phenomena to the heat-induced activation is being investigated in our laboratory.

Although the mechanism of heat activation is unclear at the present time, two explanations seem possible. Enzymatic activity depends to a great extent upon the structure of the enzyme protein, and heat-induced conformational changes in this structure thus may affect activity. In particular, subunit association and dissociation may have profound effects on activity. For example. cold-induced inactivation of pyruvate carboxylase results from dissociation of the enzyme protein into subunits $(22$, 26); subsequent heat treatment restores enzymatic activity by allowing reassociation of the subunits to tetramers. There is evidence that the cystathionine synthase from rat liver exists as a tetramer (15). Whether this is also true of the human liver enzyme is not known, but the finding that obligate heterozygotes for synthase deficiency generally exhibit much less than the $50 \%$ of the mean control value expected on the basis of a simple genedose relationship suggests that the human enzyme protein is polymeric rather than monomeric $(9,25)$. In that case, heatinduced changes in the conformation of the synthase molecule could affect subunit association and the spatial arrangement of binding sites and thereby increase activity by, for example. increasing affinities for coenzyme and/or substrates. An alternative explanation of the activation would involve the release or destruction of an inhibiting substance, resulting in an apparent activation of the enzyme. In this context, a heat-labile enzyme that specifically degrades the apoproteins of PLP-dependent enzymes has been reported to occur in small intestine and in skeletal muscle of the rat (13).

Irrespective of the mechanism of activation, the difference in the response to heat of synthase from affected invididuals appears to be a property by which normal enzyme and that from deficient individuals can be distinguished qualitatively. In addition, in vivo administration of vitamin $B_{6}$ in the form of pyridoxine- $\mathrm{HCl}$, which in these responsive patients increased hepatic cystathionine synthase activity and ameliorated the biochemical abnormalities in plasma and urine, has been shown to restore the potential for activation to the patients' enzyme. Thus, the in vivo therapy with vitamin $B_{6}$ does have some, as yet unexplained, effect on the in vitro behavior of eystathionine synthase.

\section{CONCLUSION}

Heat-induced activation of human cystathionine synthase was demonstrated in extracts of liver from normal control subjects. This property was lacking in enzyme from the synthase-deficient individuals who were studied before administration of pyridoxinc. Restoration of the activation phenomenon was achieved by pyridoxine administration in vivo, which, in these responsive patients, also alleviated the biochemical abnormalities of the discase.

Heating enzyme preparations for more than 4 min resulted in inactivation. The addition of PLP to normal enzyme before heating completely protected it from inactivation for the duration $(30 \mathrm{~min})$ of the experiment.

\section{REFEREN(ES AND NOTES}

1: Barber, G. W., and Spaeth. G. L.: Pyridoxine therapy in homocystinuria Lancet, i: 337 (1967)

2. Baudit, A. L.. and Nichols. B. L.: Residual altered $\alpha$-mannosidase in human mannosidosis. Biochem. Biophys. Res. Commun., 68: 292 (1976)

3. Carson. N. A. J., Dent, C. E., Field, C. M. B., and Gaull, G. E.: Homocystinuria: (linical and pathological review of ten cases. J. Pediat., 66: 565 (196.5)

4.. Carson, N. A. J.. and Raine, D. N. (eds.): Inherited Disorders of Sulfur Metabolism (Churchill-Livingstone, London, 1971).

5. Finkelstein, J. D., Kyle, W. E., and Harris, B. J.: Methionine metabolism in mammals: Regulatory effects of $S$-adenosylhomocysteine. Arch. Biochem. Biophys., 165: 774 (1974). 
6. Finkelstein. J. D., Kyle. W. E., Martin. J. J.. and Pick. A.: Activation of cystathionine synthase by adenosylmethionine and adenosylethionine. Biochem. Biophys. Res. Commun.. 66: 81 (1975).

7. Finkelstein, J. D., Mudd, S. H. Irreverre. F., and Laster, L.: Homocystinuria due to eystathionine synthase deficiency: The mode of inberitance. Science. 146: $785(1964)$

8. Fleisher, L. D., Longhi, R., Tallan, H. H., and Gaull, G. F.: Manuscript in preparation.

9. Fleisher, L. D., Tallan, H. H., Beratis, N. G.. Hirschhorn, K., and Gaull. G E.: Cystathionine synthase deficiency: Heterozvgote defection using cultured skin fibroblasts. Biochem. Biophys. Res Commun.. 55: 38 (1973).

10. Gaull. G. F., Rassin. D. K., and Sturman. J. A.: Enzymatic and metabolic studie's in homocystinuria: Effects of pyridoxine. Neuropadiatric. 1: 190 $(1969)$.

11. Gaull. G. E.. Sturman. J. A., and Schaffner, F.: Homocystinuria due to cystathionine stnthase deficiency: Enzymatic and ultrastructural studies. J. Pediat., 84: 381 (1974)

12. Holten, D., Wicks, W. D., and Kenney. F. T.: Studies on the role of vitamin $B_{6}$ derivatives in regulating tyrosine a-keteglutarate transaminase activity in vitro and in vivo. J. Biol. (hem., 242: 1053 (1967).

13. Katunuma, N.. and Kominami, S.: A new enzyme that specifically inactivates apoprotein of pyridoxal enzymes. Biochem. Biophys. Res. Commun., 45 $70(1971)$

14. Kim Y J and Rosenterg. I F. On the mechanism of pyridoxine responsive homocystinuria. 11. Properties of normal and mutant cystathionine $\beta$ synthase from cultured fibroblasts. Proc. Natl. Acad. Sci. U. S. A., 71 $4821(1974)$

15. Kimura. H. and Nakagawa. H.: Studies on cystathionine synthase: characteristies of purified rat liver enzyme. J. Biochem. 69: 711 (1971)

16. Litwack. ( $3 .$. and Rosenfeld, S.: Coenzyme dissociation, a possible determinant of short half-life of inducible enzymes in mammalian liver. Biochem. Biophys. Res. Commun.. 52: 181 (1973).

17. Lowry. O. H. Rosebrough. N. J.. Farr. A. L... and Randall, R. J .: Protein measurement with the Folin phenol reagent. J. Biol. (Chem., 193: 265 (1951).

18. McAlpine, P. J.. Hopkinson. D. A... and Harris. H.: Thermostability studies on the isozymes of human phosphoglucomutase. Ann. Hum. Genet., 34: 61 (197()).

Copyright o 1977 International Pediatric Research Foundation, Inc
19. Schimke, R. N., Mckusick, V. A., Huang. T.. and Pollack, A. D.: Homocystinuria: Studies of 20 families with 38 affected members. J. Amer. Med Ass. 193:87 (1965).

20. Mudd S $\mathrm{H}$ Fidwards, W A Lech, P M Brown M S and Laster, L. Homocystinutia due to cystathionine synthase deficiency: The effect of pyridoxine. J. (lin. Invest.. 49: 1762 (197(1))

21. Mudd S. H. Finkelstein, J. D. Irreverre, F.. and Laster, L.: Homocystinuria: An enzmatic defect. Science, 14.3: 1443 (1964)

22. Scrutton, M. C.. and Utter, M. F.: Pyruvate carboxylase. 3. Some physical and chemical properties of the highly purified enzyme. J. Biol. Chem., 240) $1(1965)$.

23. Singer $\mathrm{S}$ and Mason, M. Studies of the in vitro and in vive effects of conjugated seroids and carboxylic acids on hepatic tyrosine transaminase in the rat. Biochim. Biophys. Acta, 146: 452 (1967)

24. Tillan, H. H. Pascal, T. A., Schneidman, K., Gillam. B. M., and Gaull G. E.: Homolanthionine synthesis by human liver cystathionase. Biochem. Biophys. Res. Commun.. 43: 303 (1971).

25. Uhlendorf, B. W. (onerly, F. B., and Mudd, S. H.: Homocystinuria: Studies in tissue culture. Pediat. Res.. 7: 645 (1973)

26. Valentine, R. C Wrigley, N. G., Scrutton, M. C., Irias, J. J., and Utter, M. F. Pyruvalte carboxylase, VIII. The subunit structure as examined by clectron microscopy. Biochemistry. 5: 3111 (1966)

27. This study was supported in part by the New York State Department of Mental Hygiene; National Institutes of Health (linical Genetics Center Grant GM19443: National Institutes of Health Grant RR (00)(1) 1. Division of Research Resources, General Clinical Research (enter Branch; and the Lalor Foundation.

28. We thank Doctors M. Pastrana, I. Krasna, and M. Colombo for providing the liver biopsies and Mr. Russell Mallen and Mrs. Susan Sansevero for expert technical assistance. Special thanks are given to the " $B$ " family, without whose extraordinary cooperation and interest in research this study could not have been done.

29. Requests for reprints should be addressed to: (i. F. Gaull. M.D.. Department of Pediatric Research. New York State Institute for Basic Research in Mental Retardation, 1050 Forest Hill Rd.. Staten Island, N. Y. 10314 (USA)

30. Received for publication February 18, 1976

31. Accepted for publication August 20, 1976

Printed in U.S.A.

\title{
Palmar Crease Variants and Their Clinical Significance: A Study of Newborns at Risk
}

\author{
H. DAR, R. S( HMIDT, ANI) H. M. NITOWSKY'
}

The Rose F. Kennedy (enter for Research in Menal Retardation and Human Development, and Department of Pediatrics, Alhert Einstein College of Medicine of Yeshiva University, Bromx. New York, USA

\begin{abstract}
Summary
An analysis of palmar crease variants was carried out in a group of "at risk" newborns, without any evident congenital anomalies. This group consisted of 108 prematures, 74 infants who were small for gestational age, 62 newborns with history of gestational complications, and 46 newborns with a history of intrauterine methadone exposure.

A system of classification was developed based on observations of 500 normal newborns as control subjects, 466 normal mothers, and 200 normal children. The palmar crease variants can be divided into four main groups, schematically presented as normal variants, simian crease and its variants, Sydney line and its variants, and another group of unusual variants which do not fit into the other groups. A study of these groups revealed that familial components, race, sex, and age are factors that can
\end{abstract}

influence the expression of palmar crease patterns. There is an increased frequency of abnormal creases in each of the groups of "at risk" newborns. Moreover, there is an apparent association of interrupted transverse creases and intrauterine methadone exposure.

\section{Speculation}

Our findings suggest that examination of palmar creases and the demonstration of variant patterns may provide a useful. objective indicator of possible abnormal fetal development. Since it is important to utilize a standard scheme in routine newborn examination, both to identify palmar crease variants and to establish a baseline for comparative studies, a system for classification of palmar creases is presented. 